\title{
珠江三角洲客货运量位序一规模 分布特征及其变化
}

\author{
李 涛 ${ }^{1}$, 曹小曙 ${ }^{2,3,4^{*}}$, 杨文越 ${ }^{3}$
}

(1. 广东财经大学地理与旅游学院,广州 $510320 ; 2$. 陕西师范大学交通地理与空间规划研究所,西安 710062;

3. 中山大学城市与区域研究中心,广州 510275; 4. 陕西师范大学西北国土资源研究中心, 西安 710062)

\begin{abstract}
摘 要: 客货流地理是交通地理学研究的传统重要领域。本文利用位序一规模分布理论, 对 1980-2010年珠江三角 洲客货运量等级规模结构分布特征及其变化进行研究。结果表明: 客货运量规模的 $q$ 值均大于 1 , 符合位序一规模 分布特征, 但客运规模分布更显著。客运量 $q$ 值先减小后增大, 呈现出非均衡一相对均衡一非均衡演变特征; 货运 量 $q$ 值逐渐降低, 呈现出非均衡一相对均衡演变特征。在空间格局方面, 客运空间格局呈现出由初期以广州为单 中心向心型客运联系向穗莞深多中心客运联系转变; 珠三角产业结构趋同性及以广州为中心的放射状交通网络结 构, 使得货运空间格局呈现出长期以广州为核心单核主导特征, 主要表现为递接性联系特征。
\end{abstract}

关 键 词: 客货运量;位序一规模;齐夫(Zipf)定律;地域分布;珠江三角洲

\section{1 引言}

满足城际间生产、生活联系需求是客货运输联 系产生与发展的直接动力, 客货运量规模分布及其 变化既是交通基础设施分布的直接反映, 在更深层 次上则是区域经济社会发展和空间格局变动的重 要指标。

伴随着经济全球化和区域经济一体化进程的 加速, 基于客货流数据区域空间结构研究逐渐增 多。相关研究主要集中在客货运规模(修春亮等, 2008; 赵媛等, 2010; 刘文宇等, 2013)、基于客货流 的城市体系(Taaffe, 1962; 周一星等, 2002; 戴特奇 等, 2005; 冯长春等, 2014)以及物流地理(Hesse et al, 2004; 徐建等, 2009)研究等方面。其中, 对于客 货运规模的研究主要集中在客货运量规模时空分 布特征方面, 如张文尝等(1992)选取分布比、地域分 布非均衡系数等指标对我国客货运输联系的生成、 增长、分布和交流规律进行了深人分析; Cidell
(2010)利用基尼系数研究了郊区化背景下美国大都 市区货流的集聚与分散特征; 曹小曙等(2005)、李平 华等(2005)、吴威等(2011)分别研究了珠江三角洲和 长江三角洲客、货运量的时空分布特征, 揭示了城 际空间运输联系的特征及时空演化过程。现有客 货运规模研究多为引人各种地域分布集中度指标 进行刻画,利用位序一规模法则对客货运规模的研 究还较少。

在城市地理学领域,表征国家和区域城市规模 分布规律的理论主要有首位城市法则和位序一规 模法则(许学强等, 1997)。位序一规模法则最早由 德国学者奥尔巴赫于 1913 年提出; 1949 年齐普夫 (Zipf)对发达国家的城市进行研究表明: 发达国家 城市的位序和规模之间呈现出理想的直角双曲线 关系, 这种关系称为 Zipf 法则, 也称位序一规模法 则(姜世国等,2006)。Zipf 定律广泛应用于城市规 模(陈彦光等, 2001)、旅游(朱竑等, 2005)、交通(王静 等, 2012)、企业规模(方明月等, 2010)等各领域。

收稿日期: 2015-04;修订日期: 2015-07。

基金项目: 国家自然科学基金项目(41501120) [Foundation: National Natural Science Foundation of China, No.41501120]。

作者简介:李涛(1985-),男,山西人,博士,讲师,主要从事交通地理与城市发展研究,E-mail: taoli-2008@163.com。

通讯作者: 曹小曙(1970-), 男, 甘肃人,博士, 博导, 教授, 主要从事交通地理与土地利用研究,E-mail: caoxsh@mail.sysu.edu.cn。 
Zipf 定律分析所得的标度分区和 Zipf 参数值的变 化情况可以较好地解释客货运量规模分布的变化 特征。据此, 本文以珠江三角洲地区为例, 尝试利 用Zipf法则相关理论, 从更长时间尺度(1980-2010 年)研究客货运量位序一规模时空分布特征, 尝试 为解析城际间客货运量规模分布的变化规律寻求 新的路径,进而为制定区域交通基础设施投资政策 提供参考。

\section{2 数据来源与研究方法}

\section{1 数据来源}

本文以珠江三角洲作为研究区域, 以 2005 年行 政区划为基准,选取县域(县级市、区)与合并后的地 级以上城市市区作为研究单元, 其中县级单元 20 个, 地级市及城市市区 9 个 ${ }^{(1)}$ 。位序一规模分析所用 基础数据来自《广东省县(区)国民经济统计资料: 1980-1990》、2001年、2011 年广东省各地市统计
年鉴。

选取 1980、1990、2000 和 2010 年 4 个等时间间 隔年份进行分析。1980-2010年,珠三角地区客货 运能力大幅度增长, 客货运年平均增长率分别达到 了 $15.75 \%$ 和 $13.63 \%$ (图 1-2)。1980年,与珠三角地 区较低的经济社会发展水平相适应, 客货运输量较 小, 分别为 9246 万人次和 9618 万 $\mathrm{t}^{2}$ 。随着珠三角 地区改革开放步伐的加快, 交通运输基础设施和社 会经济获得持续稳定的增长, 有效地支撑了快速增 加的客货运量需求, 2010 年客运量和货运量分别达 393004 万人次和 150221 万 $\mathrm{t}$ 。从客货运输结构来 看, 珠三角地区一直保持着以公路运输为主导的运 输结构,一方面是由公路运输技术经济特性所决定 的,另一方面,随着时间成本在区域发展过程中的 重要性日益增强,大规模发展的高速公路分担了很 大一部分客货运输。

\section{2 位序一规模法则}

不同时段客货运量规模变化在空间上的投影

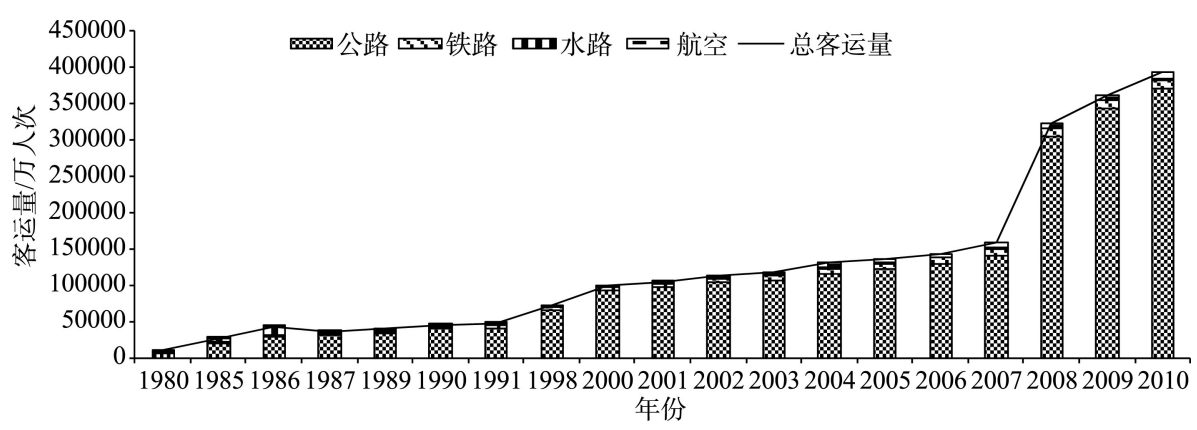

图 1 1980-2010年珠三角地区客运量规模增长变化

Fig.1 Passenger flow of the Pearl River Delta, 1980-2010

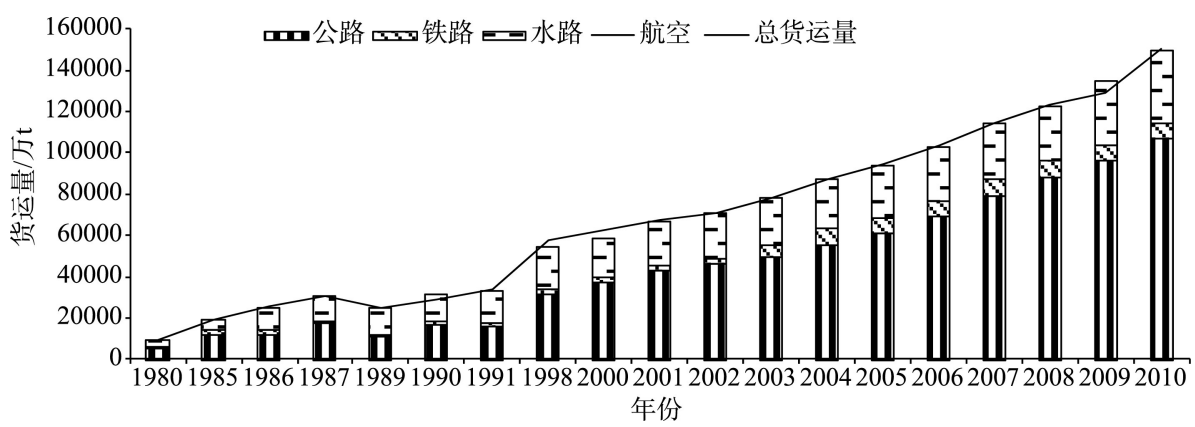

图 2 1980-2010年珠三角地区货运量规模增长变化

Fig. 2 The change of freight volume of the Pearl River Delta, 1980-2010

(1)广州市区(广州)、深圳市区(深圳)、佛山市区(佛山)、珠海市区(珠海)、惠州市区(惠州)、江门市区(江门)、肇庆市区(肇庆)、东莞、中山、番禺、花 都、从化、增城、宝安、南海、三水、顺德、高明、斗门、惠东、惠阳、博罗、新会、鹤山、开平、恩平、台山、高要、四会。

(2)为保证数据统一、连续性, 此处统计数据珠三角包括广州、东莞、深圳、惠州、佛山、中山、珠海、江门、肇庆 9 个地级市全部。 
形成了客货运量位序一规模地域分布变化规律。 借用城市地理学的位序一规模理论(许学强等, 1997), 对城市位序一规模关系式进行客货运量规 模结构转换。假设要评价 $K$ 个城镇的客货运量规 模结构, 用各城镇的客货运量规模替换城镇人口, 则有:

$$
\begin{aligned}
& P_{K}=P_{1} K^{-q} \\
& F_{K}=F_{1} K^{-q}
\end{aligned}
$$

式中: $K$ 为研究城镇单元序号 $(K=1,2,3, \cdots, N, N$ 为 所有城镇总数); $P_{K}$ 和 $F_{K}$ 分别为序号 $K$ 的城镇客运 量和货运量规模; $P_{1}$ 和 $F_{1}$ 分别为首位城镇的客运量 和货运量规模, $q$ 为 Zipf 参数。对上式两边取自然 对数, 可得:

$$
\begin{aligned}
& \ln P_{K}=\ln P_{1}-q \ln K \\
& \ln F_{K}=\ln F_{1}-q \ln K
\end{aligned}
$$

如果式(3)、(4)成立, 则该研究区域的客货运量 规模结构符合 Zipf 定律, 其规模分布呈帕累托分布 模式。无标度区和 Zipf 参数是描述位序一规模分 布的两个重要指标。无标度区为相关系数 $R^{2}$ 较大 的位序一规模分布范围, 涵盖了位序一规模分布范 围内的城镇节点。Zipf 参数 $q$ 的变化则反映了客货 运量规模的空间分布形态变化。其值等于或大于 1 时, 客货运量城镇节点的规模等级结构呈帕累托分 布模式, 城镇节点客货运量的变差较大, 中间位序 节点城镇较少; 随着 $q$ 的变小, 其规模等级结构的差 异也在缩小, 中间位序节点增多; 当 $q$ 逐渐变为小于 1 时, 客货运量城镇节点的规模等级结构呈对数正 太分布模式, 即节点城镇间客货运量的变差较小, 中间位序节点较多。

具体分析思路为: 先判断研究时段内珠三角地 区客货运量位序一规模分布是否满足 Zipf 法则, 即 分别将该地区客货运量按照规模从大到小进行排 序, 将客货规模序号和对应客货运量规模数据绘在 双对数坐标图上, 并观察其拟合态势, 如果二者存 在回归拟合函数关系, 则表明珠三角地区客货运量
的位序一规模分布符合Zipf法则。在此基础上,进 一步研究其规模分布的演变特征。

\section{3 客运量位序一规模分布演化特征}

改革开放以来,珠三角各地市抓住改革开放的 机遇, 结合自身条件,采取各种灵活措施,利用境内 外资金、技术和人才,通过自下而上工业化和城镇 化模式, 实现了经济社会的快速发展。与此相适 应, 客运规模呈现出快速增长的发展态势。前述对 珠三角地区 1980-2010年客运量的历史数据的分析 可见,该地区客运量规模处于一个动态的增长过 程。利用公式(3)和(4), 对珠三角地区 29 个城镇单 元客运量位序一规模分布进行双对数拟合, 拟合结 果如表 1 和图 3 所示。不难看出, 研究时段内各节 点城镇的客运量规模和其位序之间都存在一条拟 合直线, 亦即有一个无标度区, 且拟合优度系数均 大于 0.9 , 表明珠三角地区客运量规模的分布符合 Zipf法则。

\section{1 位序一规模变化特征}

改革开放以来, 珠三角地区的客运量位序一规 模发生了显著的变化。1980年,客运量规模前三位 的城市分别为广州、佛山和肇庆。改革开放之初的 广州作为华南地区的政治、经济、文化中心,在珠三 角地区具有绝对优势, 客运量规模达 4000 万人, 为 居于第二位的佛山市 2.4 倍。肇庆作为当时珠三角 西翼中心城市和交通枢纽,其客运量规模为 778 万 人。进人 1990 年代后, 随着各城市经济社会快速发 展, 1980年代初期所形成的客运量位序一模分布在 不断发生更替。特别是深圳、东莞和珠海三地, 其 中, 深圳从 1980 年的第 9 位上升到了 2010 年的第 1 位, 东莞从 1980年代的第 5 位上升到了 2010 年代的 第 3 位,珠海从 1980 年代的第 16 位上升到了 2010 年的第9位。究其原因,与社会经济发展和交通基 础设施的建设等因素有关。1980年代,珠三角地区

表 1 珠三角地区旅客运量位序一规模分布无标度区范围和 Zipf 参数

Tab.1 Non-scaling range and Zipf parameter of rank-size on passenger flow in the Pearl River Delta

\begin{tabular}{ccccc}
\hline 年份 & 无标度区范围 & 拟合方程 & Zipf 参数 $(q)$ & 拟合优度 $\left(R^{2}\right)$ \\
\hline 1980 & $1 \sim 26$ & $y=-1.4551 x+8.3958$ & 1.4551 & 0.9371 \\
1990 & $1 \sim 29$ & $y=-1.2445 x+9.6219$ & 1.2445 & 0.9479 \\
2000 & $1 \sim 29$ & $y=-1.3594 x+10.670$ & 1.3594 & 0.9327 \\
2010 & $1 \sim 29$ & $y=-1.6020 x+12.492$ & 1.6020 & 0.9406 \\
\hline
\end{tabular}



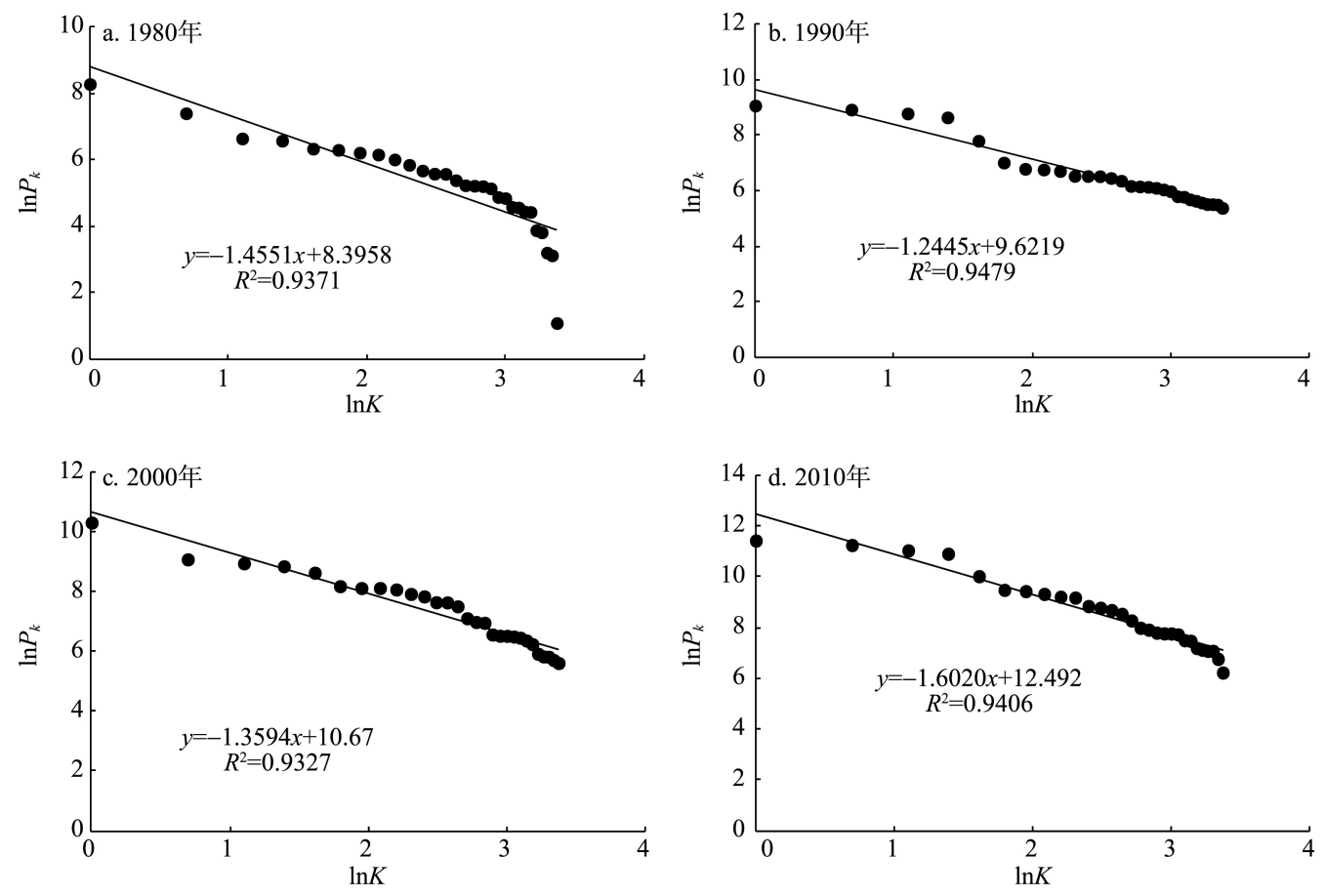

图 3 珠三角地区客运量位序一规模分布双对数拟合图

Fig.3 The $\ln -\ln$ graph on rank-size of passenger flow in the Pearl River Delta

形成了以广州为核心的单中心格局, 广州成为珠三 角地区唯一的主枢纽。随着深圳、东莞等地经济社 会迅速发展, 客运需求必然进一步增长, 再加上这 一地区交通基础设施的集中建设, 满足了经济社会 发展所产生的客运需求, 从供需两方面促进了深圳 和东莞等城市客运规模的增加和位序的提升。

从各城市的位序变化来看, 其客运量规模增长 速度亦存在着动态不平衡的特征。根据其客运量 规模变化和位序变化之间的关系, 可将研究时段内 珠三角各城镇分成以下三种类型: (1)平稳型。规模 持续增长, 但历年位序不变或者变化很小, 包括广 州、中山、顺德、博罗、高明和高要。其中, 广州的位 序从 1980 年代的第 1 位向下浮动到了 2010 年的第 3 位; (2)缓慢增长型。虽客运量规模在增加, 但在整 个客运量等级规模体系中的位序却降低了, 包括佛 山、肇庆、江门、惠州、台山、新会和恩平等城市。其 中, 肇庆位序从 1980 年的第 3 位降至 2010 年的第 20 位; (3)加速增长型。表现为客运量规模和位序同 期得到较快提升, 包括深圳、花都、珠海、增城、斗 门、宝安、从化、南海等市区。其中, 增加幅度最大 的为宝安, 从 1980 年的第 25 位提升至 2010 年的第 4 位。

\section{2 客运量空间格局特征及其变化}

Zipf 参数 $q$ 值的变化主要表征客运量规模空间
格局形态的变化。 $q$ 值 $\geqslant 1$, 客运量等级规模结构呈 帕累托分布模式, 随着 $q$ 值逐渐减小, 客运量规模等 级结构的差异相应变小, 导致居于中间位序的城镇 单元逐渐增多; 当 $q$ 值 $<1$ 时, 客运量等级规模结构 转变为对数正态分布。具体来看, 各年份的 $q$ 值均 大于 1 (表 1$)$, 表明珠三角地区客运等级规模结构呈 现为帕累托分布模式,各市客运量规模变差较大。 1980 年, 无标度区内首位城市广州的客运规模为 4000 万人, 未位城镇惠阳为 3 万人。 2010 年, 无标 度区内首位城市深圳的客运规模为 92639 万人, 末 位城镇恩平为 514 万人, 相差约 180 倍, 变差逐渐增 大。四个年份的Zipf参数 $q$ 值变化轨迹呈现出非均 衡一相对均衡一非均衡发展特征。1980年, $q$ 值为 1.4551, 客运量空间集中程度高, 广州和佛山的客运 量合计占当年全区客运量总规模的 $44.91 \%$ 。从 $1980-1990$ 年, $q$ 值下降到 1.2445 , 客运量空间分布 集中程度有所下降, 中间位序城镇逐渐增多。进人 1990 年代以后, 集中程度转而又开始上升, 特别是 深圳的崛起和东莞的发展, 逐步形成了穗深港发展 走廊, 沿线地区客运量规模也急速增加, $q$ 值进一步 上升到了 2010 年的 1.6020 。

图 4 分别表示了 $1980 、 1990 、 2000$ 和 2010 年四 个时点珠三角地区各市的客运量分布格局。1980 年,珠三角地区客运量形成了以广州为核心的单中 

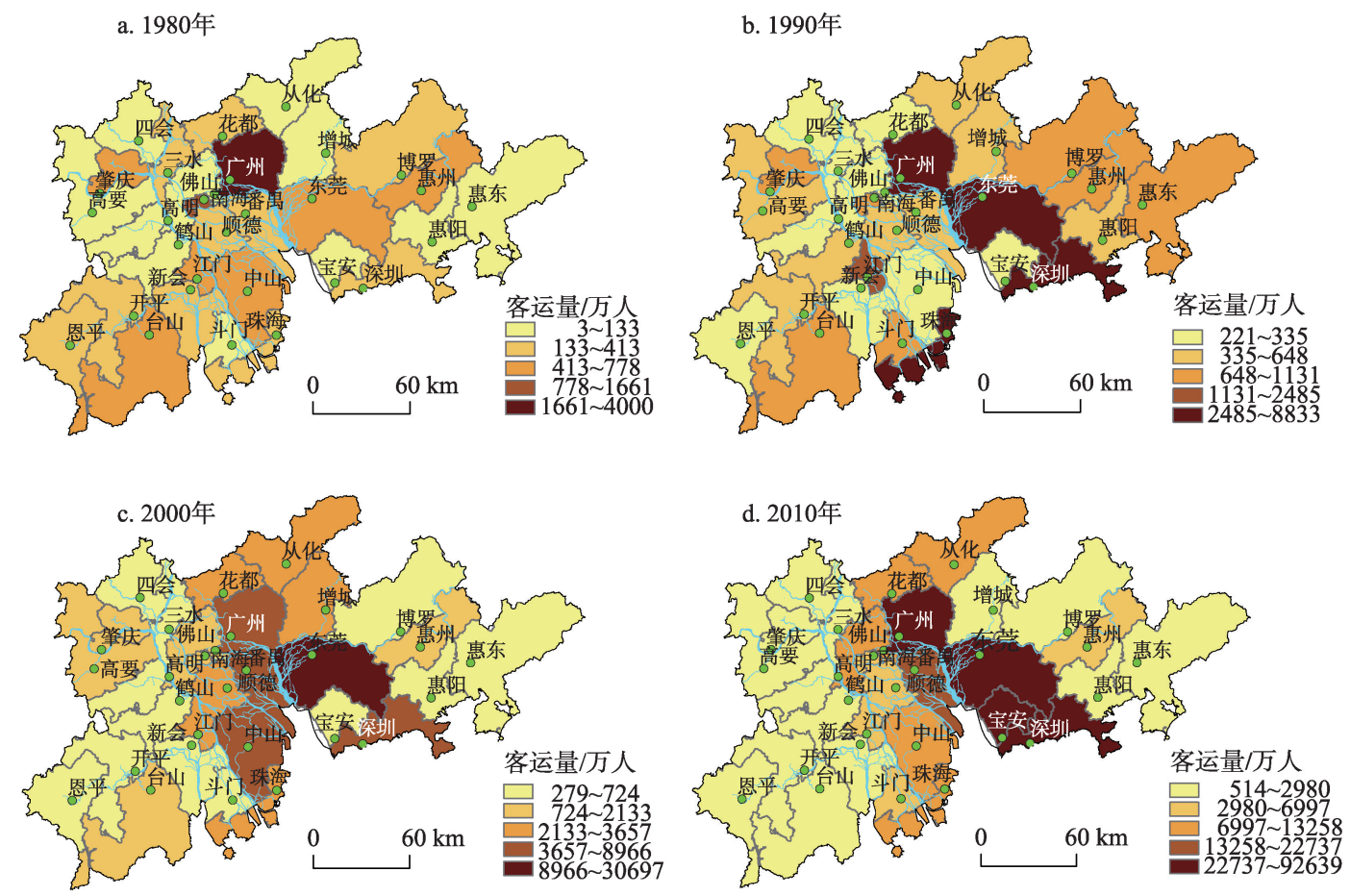

图4 珠三角地区客运量地域分布格局

Fig. 4 Spatial distribution of passengers in the Pearl River Delta

心向心型客运联系, 即以广州为中心形成的向心型 客运联系。到 1990 年,随着珠三角地区其他城市经 济社会发展水平的迅速提高, 特别是深圳、珠海和 东莞三地的客运量迅速增加, 所占比重分别上升到 $20 \% 、 15 \%$ 和 13\%。相应地, 改革开放初期广州的单 中心格局逐渐演变为多中心, 即围绕多个中心形成 的客运联系网络。进人 2000 年以后, 前两阶段所形 成的核心地区进一步扩大,形成了以广州、佛山、深 圳和东莞为核心地带, 向外围逐渐递减分布态势。

\section{4 货运量位序一规模分布演化特征}

对珠三角地区各年份货运规模进行排序, 并对 位序和对应货运量进行双对数拟合, 结果如表 2 和 图 5 所示。四个特征时点货运规模与其位序之间存 在一条拟合直线, 拟合相关系数 $R^{2}$ 均大于 0.90 , 但
与客运量拟合曲线相比,位于前几位的城市货运规 模要远远大于其他城镇。为了准确检验历年来珠 三角地区各城市货运规模变化状况, 本文同时计算 了历年货运规模首位度指标。

\section{1 位序一规模变化特征}

1980-2010年间, 珠三角地区货运规模首位城 市均为广州, 4 个时间段货运规模首位度值分别为 $5.71 、 6.01 、 3.63$ 和 1.18 。表明广州处于珠三角地区 乃至广东省的货运枢纽地位。同时,首位度值降低 也表明该枢纽地位绝对优势在逐渐弱化,位序一规 模发育态势越来越明显。1980年,货运规模居于第 二、三位的城市分别为肇庆和高要, 分别达 701 万 $\mathrm{t}$ 和 607 万 $\mathrm{t}$ 。改革开放初期, 水运在货物运输方式中 占有重要位置, 肇庆地处联接两广的水上动脉的西 江沿岸, 担负着西南各省物资出口或转粤、闽等地 的水上交通要道,来往于两广的大宗货物均在肇庆

表 2 珠三角地区货物运量位序-规模分布无标度区范围和Zipf 参数

Tab.2 Non-scaling range and Zipf parameter of rank-size on freight in the Pearl River Delta

\begin{tabular}{cccccc}
\hline 年份 & 无标度区范围 & 拟合方程 & Zipf 参数 $(q)$ & 拟合优度 $\left(R^{2}\right)$ & 首位度 \\
\hline 1980 & $1 \sim 24$ & $y=-1.1480 x+7.9481$ & 1.1480 & 0.9332 & 5.71 \\
1990 & $1 \sim 24$ & $y=-1.0580 x+8.7960$ & 1.0580 & 0.9186 & 6.01 \\
2000 & $1 \sim 27$ & $y=-1.1043 x+9.7763$ & 1.1043 & 0.9257 & 3.63 \\
2010 & $1 \sim 27$ & $y=-1.1001 x+11.408$ & 1.1001 & 0.9356 & 1.18 \\
\hline
\end{tabular}



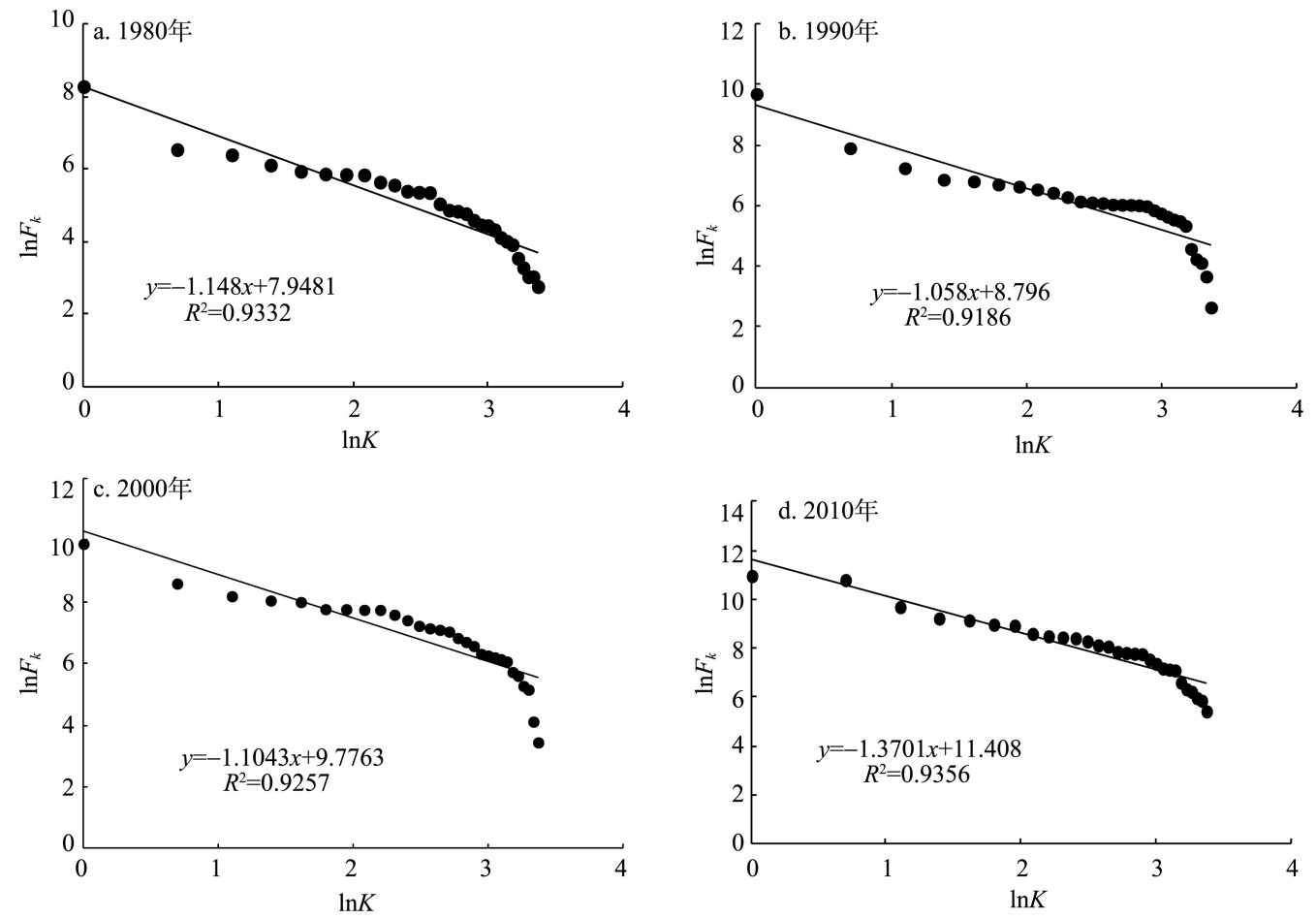

图 5 珠三角地区货运量位序一规模分布双对数拟合图

Fig.5 The ln-ln graph on rank-size of freight flow in the Pearl River Delta

转运, 决定了这一时期肇庆货运量规模位居前列的 特征。1990年代以后,随着水运货运优势地位的逐 渐下降,加之这一时期珠三角地区加工制造业的大 规模崛起, 货运量逐渐向广佛一东莞一深圳一线地 区集中。例如, 深圳从 1980 年代的第 4 位上升到了 2010 年的第 2 位, 珠海从 1980 年代的第 26 位上升 到 2010 年的第 11 位, 东莞从 1980 年代的第 8 位上 升到了 2010 年的第 3 位。

根据各市货运量规模变化和位序变化之间的 关系, 将研究时段内珠三角各城市分为以下三种类 型: (1)平稳型。规模持续增长, 但历年位序不变或 者变化很小,包括广州、深圳、南海、中山、惠阳、惠 东和鹤山。如惠阳在近 30 年来位序一直没有改变; (2)缓慢增长型。规模在增加, 但在整个货运量等级 规模体系中的位序却在下降,包括肇庆、高要、佛 山、花都、江门、新会、开平、台山以及恩平等市, 除 佛山和花都外, 主要集中分布于珠三角西翼地区。 如肇庆位序从 1980 年的第 2 位大幅降至 2010 年的 第 20 位; 3加速增长型。表现为货运量规模在增 加, 且位序也相应上升, 包括东莞、宝安、顺德、惠 州、斗门、从化、博罗和珠海等市区。

\section{2 货运量空间格局特征及其变化}

从 Zipf 参数 $q$ 来看, 各年份货运量 $q$ 值均大于 1
(表 2), 表明珠三角地区货运规模等级结构呈现帕累 托分布模式,各个城市间货运量规模变差较大。 1980 年, 无标度区内首位城镇广州的货运规模为 4000 万 $\mathrm{t}$, 末位城镇博罗的货运规模为 51 万 $\mathrm{t}$, 两者 相差了 78 倍; 2010 年, 无标度区内首位城镇广州的 货运规模为 57461 万 $\mathrm{t}$, 末位城镇惠阳的货运规模为 387 万 $\mathrm{t}$, 相差 148 倍, 变差逐渐增大。 $q$ 值从 1980 年 的 1.1480 减至 2010 年 1.1001 , 说明整体上珠三角地 区货运量规模分布趋于分散的力量大于集中的力 量, 与中间位序城镇货运规模增大有关。四个年份 的 Zipf 参数 $q$ 值变化轨迹呈现出非均衡一相对均衡 演变特征。不同于客运量,随着社会经济的发展和 产业结构的升级, 货运量增长呈现出逐渐放缓的态 势(张文尝等, 1992; 冯旭杰等, 2012)。改革开放初 期, 工业及交通网络主要集中在广州、肇庆等地区, 相应地, 货运量也多集中于这些地方, 直接决定了 1980 年代珠三角地区货运量非均衡分布的基本格 局, 广州、肇庆两地货运量合占全区的 $49.01 \%$ 。后 期,随着珠三角其他城市大规模利用境内外资金、 技术和人才推进经济发展以及核心城市产业结构 转型升级,货运量的空间集中程度逐渐下降, 呈现 出相对均衡化态势。

图 6 分别表示了 1980、1990、2000 和2010年四 

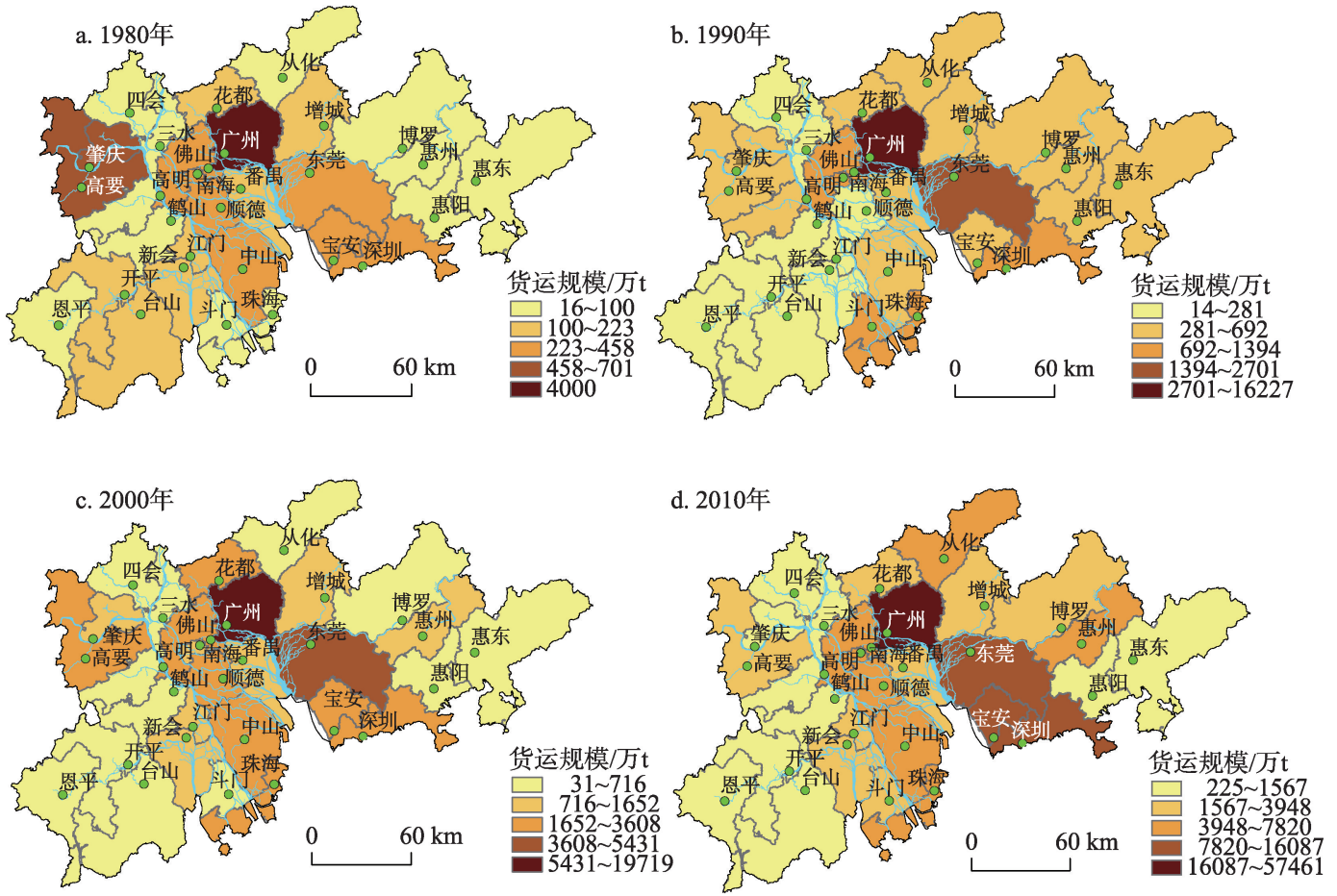

图 6 珠三角地区货运量地域分布格局

Fig.6 Spatial distribution of freight in the Pearl River Delta

个时点珠三角地区各市的货运量分布格局。在研 究时段内,珠三角地区货运空间结构长期呈单中心 格局特征。在四个研究年份, 广州一直是珠三角地 区货运规模中心,所占比重分别达 $41.71 \% 、 52.43 \%$ 、 $32.88 \%$ 和 $29.02 \%$, 形成了递接性货物交流联系。在 市域尺度上, 逐渐形成了东莞、深圳、珠海等货运枢 纽点, 促进了货运量在空间分布上的均衡化趋势。

货运量与客运量地域分布具有较大差异。究 其原因, 主要是与珠三角地区较低的货运空间互补 性和交通基础设施空间格局有关。货运空间互补 较弱主要与珠三角地区产业结构趋同特征具有直 接关系。改革开放以来, 珠三角地区形成了以“三 来一补”为主要特征的外向型产业发展特征, 集中 了劳动密集型和资源密集型产业, 再加上该地区相 似的资源禀赋条件, 使得珠三角产业结构出现了一 定程度的相似性和趋同性(翁计传, 2006)。此外, 在 港澳的辐射带动下, 珠三角地区形成了以“前店后 厂”模式为特征的以轻工业主导的产业结构。各地 的产业趋同造成了空间上缺少互补性, 货物的流动 不如人员的交流频繁和广泛, 大部分货物交流都通 过广州枢纽展开。同时, 区内形成的以广州为中心 的放射状运输网络也是导致广州 “一家独大”特征 的重要原因。

\section{5 客货运量位序一规模分布特征的影 响因素}

通过上述对珠三角地区客货运量位序一规模 分布特征的分析,无论客运量还是货运量来看, 在 研究时段内的位序一规模分布特征均有较大的变 化, 而且这种变化在客运量和货运量量之间还存在 差异。关于客货运量位序一规模分布的影响因素, 相关研究认为主要与经济发展水平、人口规模以及 交通基础设施水平直接相关。在客运量变化影响 因素中,经济发展水平对客运量变化的影响最为明 显。在改革开放初期, 由于经济发展水平较低, 人 口增长较快, 人们出行需求较低, 仅限于必需的出 行需求。城际间的联系具有等级特征,广州作为华 南地区的行政、经济和文化中心,形成了以广州为 中心的单核心向心型客运联系模式。随着经济加 速发展, 在收人水平和闲暇时间增加的前提下,人 们出行需求也逐渐增加, 决定了研究时段内客运量 逐渐增长的态势; 同时城际间的联系也增多, 相应 地形成了多中心客运联系模式。随着经济加速发 展, 在收人水平和闲暇时间增加的前提下, 人们出 行需求也逐渐增加, 决定了研究时段内客运量逐渐 
增加的态势。在客运量空间格局上, 与珠三角地区 社会经济发展的空间差异一致,客运量地域分布特 征也呈现出从穗莞深走廊 $\rightarrow$ 珠三角东翼 $\rightarrow$ 珠三角 西翼逐渐递减的格局特征。为了定量揭示客货运 量位序一规模特征及其变化的影响因素, 选取了 1980-2010 年人口规模、GDP 和路网规模三个重要 因素分别与客或运量进行相关分析。结果显示, 代 表社会经济发展水平的 GDP 与客运量变化的相关 关系最为密切, 相关系数 $\left(R^{2}\right)$ 在 0.90 以上的有 13 个 城市, 在 $0.80 \sim 0.90$ 之间的有 13 个城市, 0.80 以下的 仅有开平、恩平和鹤山 3 个城市。与 GDP 相比, 人 口规模与客运量增长的相关性总体上要低于 GDP, 相关系数 $\left(R^{2}\right)$ 在 0.90 以上的城市仅有 3 个, 在 0.80 0.90 之间和 0.80 以下的各有 13 个城市。交通线路 里程增加与客运量增长之间的关系更低, 可能与本 文仅考虑交通线路里程, 而没有考虑由于线路技术 等级水平提高所引起的客运能力的增长有关。除 广州、珠海和东莞、中山相关系数在 0.80 以上外, 其 余城市的相关系数均在 0.80 以下。与客运量变化 不同,货运量变化一方面与各地市的社会经济发展 水平有关外, 另一方面也与各市的产业结构具有直 接关系。随着产业结构水平的提高, 单位产品的能 耗、所需原料以及运输需求都呈下降趋势(张文尝 等, 1992)。改革开放初期, 工业及交通网络主要集 中在广州、佛山等市, 相应地, 货运量也多集中于这 些城市, 直接决定了 1980 年代珠三角货运量分布的 不均衡性较强, 广州、佛山两地客运量在全区占比 达 55.43\%, 这种发展趋势一直持续到 1990 年, 货运 量非均衡性达到最高程度。此后, 随着广州、深圳 等地产业结构的逐渐升级, 而外围后发地区以二产 为主的产业结构导致货运量规模的不断增加, 货运 量的空间集中程度持续下降,均衡化程度不断提 高。在货运量空间格局上, 由于珠三角地区产业结 构的趋同性, 使得区内货物互补性交流较弱, 长期 形成了以广州为核心的递接性交流联系模式。 GDP 与货运量增长关系最为密切, 相关系数在 0.90 以上的城市有 12 个; 相关系数在 $0.80 \sim 0.90$ 之间的 城市有 16 个, 仅有高要的相关系数为 0.789 。交通 线路里程增长与货运量增长的关系也较为密切, 如 佛山、东莞、中山等交通基础设施发展较快的地市, 二者相关系数在 0.8 以上的城市有 5 个, 在 0.70 0.80 之间的城市有 10 个, 低于 0.70 的有 14 个。人 口规模增长与货运量增长的相关关系较弱, 相关系
数大于 0.80 的仅有番禺, 其余城市的相关系数大部 分处于 0.60 左右。

\section{6 结论与讨论}

本文以珠江三角洲为实例, 以县市为基本单 元, 借用城市地理学的位序一规模法则, 研究了 1980 年代以来珠三角客货运量位序一规模分布及 其变化特征,得到的主要研究结论如下:

(1) 位序一规模法则可以较好地刻画客货运量 空间分布特征。客货运量规模的 $q$ 值均大于 1 , 符 合位序一规模分布特征, 但客运量规模分布更 显著。

(2) 在客货运量规模结构空间形态方面, 客运 量的 $q$ 值经历了先减小后增大的变化, 表明珠三角 客运量规模分布演化表现为非均衡一相对均衡一 非均衡特征。货运量 $q$ 值逐渐降低, 表明珠三角货 运量规模分布演化表现为非均衡一相对均衡特 征。在客货运量地域分布方面, 客运量空间格局呈 现出由单中心向多中心转变的特征,货运量空间格 局则呈现出长期的单核主导特征。

(3) 区域经济社会发展水平及其格局特征决定 了客货运位序一规模分布特征及其变化。在客运 规模方面, 客运量规模随着社会经济发展水平的提 高而逐渐增加,但由于珠三角地区社会经济发展的 空间差异,造成了客运量地域分布特征相应地呈现 出了从穗莞深走廊 $\rightarrow$ 珠三角东翼 $\rightarrow$ 珠三角西翼逐 渐递减的格局特征。相应地, 客运联系也由初期的 以广州为中心的单核心向心型客运联系模式转变 为多中心客运联系模式。珠三角地区产业结构趋 同性、轻工业为主的工业结构特征, 再加上以广州 为中心的放射状交通网络结构, 导致了货运空间结 构的单核主导型特征, 表现为递接性货物联系 模式。

本文着重分析了 1980-2010年珠三角地区客货 运量规模分布变化特征。在未来研究中,可从区域 交通发展、经济社会发展、产业结构升级等方面对 规模分布变化形成的机理进行深人研究。

\section{参考文献(References)}

曹小曙, 阎小培. 2005. 珠江三角洲客、货运量的空间演化研 究 [J]. 人文地理, 17(3): 66-68. [Cao X S, Yan X P. 2005. Spatial evolution of the flow of passengers and freight 
transport in the Pearl River Delta[J]. Human Geography, 17(3): 66-68.]

陈彦光, 刘继生. 2001. 城市系统的异速生长关系与位序一 规模法则 [J]. 地理科学, 21(5): 412-416. [Chen Y G, Liu J S. 2001. Reconstructing Steindl's Model: From the Law of Allometric Growth to the Rank- Size Rule of Urban Systems[J]. Scientia Geographica Sinica, 21(5): 412416.]

戴特奇, 金凤君, 王姣娥. 2005. 空间相互作用与城市关联网 络演进: 以我国 20 世纪 90 年代城际铁路客流为例 $[\mathrm{J}]$. 地理科学进展, 24(2): 80-89. [Dai T Q, Jin F J, Wang J E. 2005. Spatial interaction and network structure evolvement of cities in term of China's railway passenger flow in 1990s[J]. Progress in Geography, 24(2): 80-89.]

方明月, 聂辉华. 2010. 中国工业企业规模分布的特征事实: 齐夫定律的视角 [J]. 产业经济评论, 9(2): 1-17. [Fang M Y, Nie H H. 2010. The stylized facts of size distribution of China manufacturing industries: A perspective of Zipf' s law [J]. Review of Industrial Economics, 9(6): 1-17.]

冯旭杰, 孙全欣, 钱壁, 等. 2012. 区域综合交通运输需求与 产业结构的协整关系分析 [J]. 交通运输系统工程与信 息, 12(6): 10-16. [Feng X J, Sun Q X, Qian K, et al. 2012. Cointegration relationship of regional integrated transport demand and industrial structure[J]. Journal of Transportation Systems Engineering and Information Technology, 12(6): 10-16.]

冯长春, 谢旦杏, 马学广, 等. 2014. 基于城际轨道交通流的 珠三角城市区域功能多中心研究 [J]. 地理科学, 34(6): 648-655. [Feng C C, Xie D X, Ma X G, et al. 2014. Functional polycentricity of the urban region in the Zhujiang River Delta based on intercity rail traffic flow[J]. Scientia Geographica Sinica, 34(6): 648-655.]

姜世国, 周一星. 2006. 北京城市形态的分形集聚特征及其 实践意义 [J]. 地理研究, 25(2): 204-212. [Jiang S G, Zhou Y X. 2006. The fractal urban form of Beijing and its practical significance[J]. Geographical Research, 25 (2): 204-212.]

李平华, 于波. 2005. 改革开放以来长江三角洲经济结构变 迁与城际联系特征分析 [J]. 经济地理, 25(3): 362-365. [Li P H, Yu B. 2005. A study on the time-spatial revolution characteristics of spatial linkage and economic structure in Yangtze River Delta[J]. Economic Geography, 25 (3): 362-365.]

刘文宇, 赵媛. 2013. 中国省际煤炭资源流动的集中程度与 位序一规模变化 $[J]$. 资源科学, 35(12): 2474-2480. [Liu W Y, Zhao Y. 2013. Concentration and rank-size distribution of interprovincial coal flow in China[J]. Resources
Science, 35(12): 2474-2480.]

王静, 刘剑锋, 孙福亮. 2012. 北京市轨道交通线网客流分布 及成长规律 $[J]$. 城市交通, 10(2): 26-32. [Wang J, Liu J F, Sun F L. 2012. Passenger demand distribution and increasing trend over Beijing rail transit network $[\mathrm{J}]$. Urban Transport of China, 10(2): 26-32.]

翁计传. 2006. 珠江三角洲工业结构趋同性研究 [J]. 世界地 理研究, 15(1): 21-26. [Weng J C. 2006. An analysis on assimilated industrial structures in Pearl River Delta[J]. World Regional Studies, 15(1): 21-26.]

吴威, 曹有挥, 梁双波, 等. 2011. 20 世纪 80 年代中期以来长 三角地区货运量动态研究 $[\mathrm{J}]$. 长江流域资源与环境, 20 (7): 843-847. [Wu W, Cao Y H, Liang S B, et al. 2011. Study on dynamics of freight volume in the Yangtze River Delta since the mid-1980s[J]. Resources and Environment in the Yangtze Basin, 20(7): 843-847.]

修春亮, 赵映慧, 宋伟. 2008. 1990 年以来东北地区铁路运输 的空间极化 [J]. 地理学报, 63(10): 1097-1107. [Xiu C L, Zhao Y H, Song W. 2008. Spatial polarization of railway transport in northeast china: 1990- 2005[J]. Acta Geographica Sinica, 63(10): 1097-1107.]

徐建, 曹有挥, 孙伟. 2009. 基于公路运输成本的长三角轴一 辐物流网络的构建 [J]. 地理研究, 28(4): 911-919. [Xu J, Cao Y H, Sun W. 2009. Construction of hub-and-spoke logistics network based on road traffic cost in Yangtze River Delta[J]. Geographical Research, 28(4): 911-919.]

许学强, 周一星, 宁越敏. 1997. 城市地理学[M]. 北京: 高等 教育出版社. [Xu X Q, Zhou Y X, Ning Y M. 1997. Urban geography[M]. Beijing, China: Higher Education Press.]

张文尝, 金风君, 荣朝和, 等. 1992. 空间运输联系: 理论研 究·实证分析・预测方法 $[\mathrm{M}]$. 北京: 中国铁道出版社. [Zhang W C, Jin F J, Rong C H, et al. 1992. Kongjian yunshu lianxi: Lilun yanjiu · shizheng · fenxi yuce fangfa [M]. Beijing, China: China Railway Publication House.] 赵媛, 牛海玲, 杨足膺. 2010. 我国石油资源流流量位序一规 模分布特征变化 [J]. 地理研究, 29(12): 2121-2131. [Zhao Y, Niu H L, Yang Z Y. 2010. Study on the rank-size distribution and variation of crude oil flow in China $[\mathrm{J}]$. Geographical research, 29(12): 2121-2131.]

周一星, 胡智勇. 2002. 从航空运输看中国城市体系的空间 网络结构 [J]. 地理研究, 21(3): 276-286. [Zhou Y X, Hu Z Y. 2002. Looking into the network structure of Chinese urban system from the perspective of air transportation [J]. Geographical Research, 21(3): 276-286.]

朱泣, 吴旗蹈. 2005. 中国省际及主要旅游城市旅游规模 $[\mathrm{J}]$. 地理学报, 60(6): 919-927. [Zhu H, Wu Q T. 2005. Study 
on tourism size of provinces and primary cities in China

[J]. Acta Geographica Sinica, 60(6): 919-927.]

Cidell J. 2010. Concentration and decentralization: The new geography of freight distribution in US metropolitan areas [J]. Journal of Transport Geography, 18(3): 363-371.
Hesse M, Rodrigue J P. 2004. The transport geography of logistics and freight distribution[J]. Journal of Transport Geography, 12(3): 171-184.

Taaffe E J. 1962. The urban hierarchy: An air passenger definition[J]. Economic Geography, 38(1): 1-14.

\title{
Rank-size distribution and evolution of passenger and freight flows in the Pearl River Delta
}

\author{
LI Tao ${ }^{1}$, CAO Xiaoshu ${ }^{2,3,4 *}$,YANG Wenyue ${ }^{3}$ \\ (1. School of Geography and Tourism, Guangdong University of Finance \& Economics, Guangzhou 510320, \\ China; 2. Institute of Transport Geography and Spatial Planning, Shaanxi Normal University, Xi'an 710062, \\ China; 3. Center for Urban \& Regional Studies, SunYat-Sen University, Guangzhou 510275, China; \\ 4. Northwest Land and Resources Research Center, Shaanxi Normal University, Xi'an 710062, China)
}

\begin{abstract}
Passenger and freight flow distribution and dynamic change are the characteristic index of regional transport patterns. This article analyzes passenger and freight flow rank-size distribution and regional patterns between 1980 and 2010 in the Pearl River Delta (PRD) area using the rank-size distribution theory. The results show that: passenger and freight flow q values were greater than 1, in line with rank-size distribution, but the distribution was more in line with the size of the passenger rank-size distribution. Passenger q value decreased and then increased, showing non-equilibrium-relative equilibrium-disequilibrium evolution characteristics. The $\mathrm{q}$ values of freight flow decreased, showing non-equilibrium-relatively balanced evolution characteristics. With regard to the spatial pattern, passenger flow shifted from a single center to multi-centers, with a macro scale "point shaft" and mesa-scale "hub and spoke" regional system. Freight flow showed a long-term pattern of monocytes leading to the macro and mesa scale "hub and spoke" system. Convergence of industrial structure in the PRD, light industry-dominated industrial structure, coupled with the single center (Guangzhou) radial transport network determined the spatial pattern of monocyte freight flow.
\end{abstract}

Key words: passenger and freight flows; rank-size; Zipf law; regional distribution; Pearl River Delta 